\title{
PEKERJA PEREMPUAN DI TAMBANG: BENTUK NEGOSIASI KESETARAAN GENDER DALAM DUNIA KERJA MASKULIN
}

\author{
Zulfatun Mahmudah
}

Corporate Communication, Postgraduate Program LSPR Intiland Tower Lt.6, Jl. Jend Sudirman Kav. 32, RT.3/RW.2, Karet Tengsin, Kota Jakarta Pusat, Daerah Khusus Ibukota Jakarta 10250 Telp. 08125533047 / 0811580924 Email : me@zulfatunmahmudah.id

\begin{abstract}
Mine is always described as a hard and risky workplace, cannot be separated from gender issues. On the other hand, currently many women are able to work in the mine, and even they have very good work performance. This research is intended to explore the factors, how they adapt and interpret their work, and how they undergo a dual role as workers and housewives. This research was conducted using a qualitative approach with phenomenological research method, in-depth interviews as a form of dialectical interaction. Respondents of this study were woman coal mining operators at PT Kaltim Prima Coal (KPC), an international scale coal mine located in East Kalimantan. The research informants are women who operate heavy equipment in the mine. The research result showed that women were able to adapt to the workplace where they were involved in, without seeing the physical differences between men and women. They are able to play a dual role as workers and housewives. It can be concluded, in the mine women are able to adapt the work situation and condition without boundary that mine is the masculine workplace. It corrects various opinions, that women are people who are marginalized by the presence of mines.
\end{abstract}

Keywords: female worker, gender, mine

\begin{abstract}
Abstrak
Tambang selalu digambarkan sebagai dunia kerja yang keras dan penuh risiko dan tidak bisa dilepaskan dari isu gender. Saat ini banyak perempuan yang mampu bekerja di tambang, bahkan memiliki prestasi kerja sangat baik. Penelitian ini dimaksudkan untuk menggali faktor pendorong, cara adaptasi, pemaknaan pekerjaan, serta peran ganda sebagai ibu rumah tangga dan pekerja. Penelitian ini menggunakan pendekatan kualitatif dengan metode penelitian fenomenologi, wawancara mendalam sebagai bentuk interaksi dialektis. Responden penelitian ini adalah operator perempuan tambang batubara di PT Kaltim Prima Coal (KPC) sebuah tambang batubara skala internasional yang berlokasi di Kalimantan Timur. Informan penelitian ini adalah perempuan yang mengoperasikan alat berat di tambang. Hasil penelitian menunjukkan, perempuan mampu beradaptasi dengan dunia kerja yang digeluti, tanpa melihat perbedaan fisik antara laki-laki dan perempuan. Mereka mampu menjalani peran ganda secara maksimal, sebagai pekerja dan ibu rumah tangga. Bisa disimpulkan, di tambang perempuan mampu beradaptasi dengan dunia kerjanya tanpa batasan tambang adalah dunia kerja maskulin. Hal ini sekaligus mengoreksi berbagai pendapat yang ada, bahwa perempuan adalah kaum yang termarginalkan oleh kehadiran tambang.
\end{abstract}

Kata kunci: pekerja perempuan, gender, tambang

\section{Pendahuluan}

Tambang selalu dikonotasikan sebagai tempat kerja laki-laki. Seperti dikatakan oleh Kathryn Robinson (1996:137) "Mining... is imbued with notions of masculinity, where men are assumed the 'natural' workers, forcing the reluctant feminine of nature to yield its hidden secrets". Apa yang disampaikan Kathryn Robinson tersebut menggambarkan bahwa tambang merupakan dunia kerja yang identik dengan maskulin, dan secara alamiah pekerjanya pun lebih cocok untuk laki-laki. Tidak hanya dihubungkan dengan gender, para pekerja 
tambang juga diasosiasikan sebagai bentuk pengambilan pekerjaan yang berisiko, kotor, dan membahayakan yang lebih pas dengan karakter maskulin. Selain itu, kehidupan pit dianggap sebagai dunia laki-laki yang cukup unik dan merupakan tempat mereka membentuk rasa solidaritas terhadap risiko yang ada. Menurut Joan Evelin (dalam Kuntala Lahiri-Dutt dan Kathryn Robinson, 2008: 125) “Workers in mines are represented as undertaking dangerous, dirty and hazardous works, characterized by a form of masculinity suitable for heroes. Pit life is perceived as a uniquely male world where the sharing of risks contributes to the formation of male solidarity".

Pendapat tersebut merupakan penggambaran bahwa dunia tambang cukup keras. Selain secara alam memang sangat tidak bersahabat bagi perempuan, sarana dan prasarana kerjanya pun tidak bersahabat dengan perempuan jika dilihat dari bentuk fisik perempuan. Pengotakan dunia kerja laki-laki dan perempuan di tambang tidak terlepas dari munculnya terminologi gender. Menurut Harriet Bradley dalam Mellisa Houghtaling (2009) gender adalah konstruksi sosial, sebuah kategori yang digunakan oleh manusia sebagai cara membagi dan memahami dunia yang mereka rasakan di sekitar mereka. Sebagai sebuah konstruksi sosial, Bradley mengakui, gender bukanlah sesuatu yang tetap melainkan bervariasi sesuai dengan waktu, tempat dan budaya.

Menurut Helen Tierney (1999), gender adalah suatu konsep kultural yang berupaya membuat pembedaan dalam hal peran, perilaku, mentalitas, dan karakteristik emosional antara laki-laki dan perempuan yang berkembang dalam masyarakat. Lebih lanjut Mansour Fakih (2013: 8) dalam bukunya yang berjudul "Analisis gender dan Transformasi Sosial" menjelaskan, konsep gender dipahami sebagai suatu sifat yang melekat pada kaum laki-laki dan perempuan yang dikonstruksi secara sosial maupun kultural. Misalnya, perempuan dikenal lemah dan lembut, cantik dan emosional. Sedangkan laki-laki sering dianggap kuat dan perkasa; gagah dan rasional. Ciri dari sifat di atas merupakan sifat-sifat yang dapat dipertukarkan. Munculnya perbedaan dalam konsep gender antara laki-laki dan perempuan dikarenakan oleh banyak hal, diantaranya dibentuk, disosialisasikan, diperkuat, bahkan dikonstruksi secara sosial atau kultural, melalui ajaran keagamaan maupun negara.

Pengotakan dunia kerja tambang yang dianggap lebih cocok untuk lakilaki, tidak terlepas dari konsep gender yang berkembang di masyarakat. Stereotip perempuan digambarkan sebagai kaum yang lemah, disisi lain tambang diasosiasikan sebagai dunia kerja yang keras. Pembedaan tersebut dikonstruksi baik secara sosial maupun kultural. Seperti yang disampaikan oleh Kuntala Lahiri-Dutt (2004:11),

Mining everywhere is commonly perceived as a uniquely male world of work where the separation of men and women's lives is almost total. Mining is seen as a dangerous, risky, dirty and hazardous work in which men go down the mines daily to earn for the families, endangering their own lives, and sharing risks that contribute to the formation of a male solidarity.

Penggambaran tambang tersebut berdampak pada munculnya bias gender 
di industri pertambangan. Menurut Riant Nugroho (2008:235) bias gender muncul manakala kepercayaan budaya dan pengaturan struktural lebih cenderung berpihak kepada laki-laki dari pada perempuan. Jika dilihat dari sudut pandang gender, kata tambang memiliki efek cenderung melemahkan perempuan dan memunculkan adanya ketidaksetaraan gender. Selain dipengaruhi oleh konsep gender, minimnya keterlibatan perempuan di tambang juga dipengaruhi oleh beberapa hal. Kuntala Lahiri-Dutt (2004:12) mengatakan,

"Three factors contribute to the differential gender impacts of mining: - The gender segregation in the workplace leading to exclusion of women from well-paying mining jobs; • The less secure and more sporadic forms of employment outside of the company are taken up by women workers; and $\bullet$ The disempowerment of women in mining communities".

Selain dihubungkan dengan konsep gender, minimnya pekerja perempuan di tambang kadang dikaitkan dengan ketidak mampuan perempuan dalam melakukan negosiasi dengan lingkungan kerjanya yang notabene didominasi laki-laki. Di sejumlah tambang, perempuan merupakan minoritas, karena umumnya pekerjaan tambang didominasi laki-laki. Bagi perempuan yang tidak mampu mengimbangi gaya kerja dan pola komunikasi yang cenderung sangat maskulin, perempuan akan lebih memilih pekerjaan yang atmosfirnya lebih cocok bagi perempuan. Dalam konteks ini, negosiasi dimaksudkan sebagai proses menghasilkan keputusan bersama, dimana orang-orang dengan tujuan atau keinginan yang berbeda berinteraksi dengan tujuan untuk menyelesaikan perbedaan-perbedaan tersebut (Hayes: 2002). Jika dikaitkan dengan komunikasi antarbudaya, Stella Ting-Toomey (1999: 40) mengatakan konsep negosiasi digambarkan sebagai proses interaksi transaksional di mana para individu dalam satu situasi antarbudaya mencoba memaksakan, mendefinisikan, mengubah, menantang, ataupun mendukung citra diri yang diinginkan.

Meski definisi negosiasi bersifat universal, namun pada praktiknya tidak jarang negosiasi dikaitkan dengan gender karena lebih sering dilakukan oleh lakilaki dibanding perempuan. Linda Babcock (2003) dalam bukunya Women Don't Ask: Negotiation and the gender Divide mengatakan bahwa kebanyakan perempuan hanya mengerjakan sesuatu dan tidak bertanya. Dalam buku tersebut digambarkan bahwa perempuan tidak mendapatkan banyak hal dalam hidupnya karena mereka tidak berpikir untuk meminta. Laki-laki meminta hal-hal yang mereka inginkan dan bernegosiasi atas keinginannya lebih sering dari pada perempuan dua hingga tiga kali lipat. Kondisi perempuan yang enggan bernegosiasi dengan kondisi dan situasi yang dihadapinya, dipengaruhi oleh beberapa faktor. Linda Babcock (2003:4) menjelaskan,

Women often worry more than men about the impact their actions will have on their relationships... Women also frequently take a more collaborative approach to problem solving than men take, trying to find solutions that benefit both parties or trying to align their own requests with shared goals.

Meski perempuan tidak terbiasa bernegosiasi, namun Linda Babcock ber- 
pendapat bahwa perempuan bisa mengatasi kecemasan mereka dan menemukan cara-cara efektif untuk bernegosiasi. Adanya pekerja perempuan di tambang sebagai operator alat berat menunjukkan bahwa perempuan mampu mengatasi kecemasan dan menemukan cara-cara yang efektif dalam bernegosiasi. Mereka bukanlah segelintir orang melainkan berjumlah ratusan. Di tambang batubara PT Kaltim Prima Coal (KPC) misalnya, jumlah perempuan yang bekerja mengoperasikan alat berat mencapai 128 orang. Mereka berasal dari berbagai latar belakang baik pendidikan, suku, maupun agama dengan tingkat usia yang sangat beragam.

Keberadaan kaum perempuan yang bekerja di tambang bisa dikatakan merupakan kelompok minoritas di tengah dominasi laki-laki. Berdasarkan data Divisi HR KPC, di tambang ini jumlah karyawan mencapai 4.517 orang, dengan komposisi laki-laki 4.205 dan perempuan 312 karyawan. Jika dilihat dari sudut pandang teori co-cultural, kondisi tersebut bisa digambarkan sebagai kelompok yang kurang terwakili dilihat dari sisi perbedaan budaya yang sangat menonjol. Menurut Mark Orbe dalam Littlejohn dan Foss (2008:181), teori ini dirancang untuk memfasilitasi pemahaman tentang bagaimana anggota kelompok co-cultural menegosiasikan perbedaan budaya mereka dengan yang lain. Orbe memilih kata cocultural daripada terminology subcultural, subordinate, dan minority, karena istilah co-cultural ingin menunjukkan bahwa tidak ada satu pun budaya dalam masyarakat yang lebih unggul terhadap budaya yang lain. Ada dua premis yang dibangun dalam teori ini. Pertama, para anggota kelompok co-cultural termarjinalkan di dalam struktur masyarakat dominan. Kedua, para anggota kelompok co-cultural memakai gaya komunikasi tertentu untuk mencapai keberhasilan ketika dihadapkan pada struktur masyarakat dominan yang cenderung menindas. Mark Orbe (dalam Littlejohn dan Foss, 2008: 181) memahami teori ini berdasar lima asumsi, yaitu :

(1)hierarchy exists in any society that privileges certain groups; (2) dominant members, on the basis of varying levels of privilege, occupy positions of power that enable them to create aIld maintain systems that reinforce their perspectives and experiences and mute those of others; (3) dominant communication systems function to keep co-cultural group members outside the centers of power; (4) while there is considerable variation across co-cultures, they share a marginalized social position within the dominant system; and (5) co-cultural group members strategically communicate to negotiate the dominant system in which they find themselves.

Para pekerja perempuan di tambang harus bisa bernegosiasi dengan berbagai hal agar bisa bertahan di tengah pekerjaan yang didominasi laki-laki. Selain didominasi lakilaki, karakteristik pekerjaan tambang juga sangat maskulin. Dilihat dari seragam yang dikenakan, pekerja tambang harus memakai sepatu safety yang cukup berat, dilengkapi rompi, helm dan celana jeans. Kendaraan yang harus dioperasikan juga berukuran sangat besar, yang tentu saja sangat tidak sesuai dengan badan perempuan. Jam kerja tambang juga berlaku shift yang mengharuskan karyawan baik laki-laki maupun perempuan bekerja siang dan malam. Jika giliran shift malam, tentu saja perempuan harus terjaga semalam suntuk di atas kendaraan yang dioperasikan. Para pekerja perempuan di tambang dituntut 
bisa menyesuaikan dengan semua kondisi tersebut.

Teori dan fakta tentang tambang memang tidak berpihak pada perempuan. Hal tersebut tidak berarti perempuan tidak mampu dan tidak mau bekerja di tambang. Ini terbukti dari banyaknya perempuan yang bekerja sebagai operator di tambang PT Kaltim Prima Coal (KPC). Berdasarkan data Human Resources KPC, perusahaan tambang batubara kelas dunia yang berlokasi di Sangatta, Kalimantan Timur itu mempekerjakan perempuan di tambang sejak tahun 1992. Mereka sehari-harinya bertugas sebagai operator yang mengoperasikan alat berat dengan ukuran sangat besar.

Di tambang tersebut perempuan melakukan pekerjaan yang sama persis dengan laki laki. Mereka bekerja dalam shift yang berdurasi 12 jam dalam setiap shift. Jika tiba giliran pada shift malam, berarti perempuan akan terjaga sepanjang malam hingga terbit matahari. Selama kurun waktu tersebut perempuan akan mengoperasikan alat berat yang ukurannya jauh melebihi kendaraan pada umumnya. Atribut yang digunakan selama bekerja juga sama antara laki-laki dan perempuan. Para operator perempuan harus memakai sepatu safety yang relatif berat, helm, dan rompi. Mereka sama-sama harus bekerja dalam standar keselamatan yang sangat ketat. Jika operator laki-laki mengemudikan alat berat di tengah hutan yang sunyi, perempuan juga melakukan hal yang sama.

Bahkan dalam sejumlah penelitian sebelumnya telah dibuktikan bahwa dilihat dari sisi keselamatan di lapangan, perempuan jauh lebih berhati-hati dan mampu meminimalisir kecelakaan tambang. Berdasarkan data health and safety $2017 \mathrm{di}$ PT KPC tidak ada Lost Time Injury (LTI) yang melibatkan operator perempuan sejak pertama kali perusahaan ini mempekerjakan perempuan di tambang tahun 1992. Seperti disampaikan Lahiri-Dutt (2004) dalam penelitiannya,

Women are more careful in their jobs and as result not one of them has had any accidents. They can also cope better with repetitive and tedious jobs, are easier to deal with, and tend to have a steadying impact on men. Above all, woman do not take time off for payers, interrupting work schedule in the field, and cope well with colleagues at the workplace.

Kehebatan pekerja perempuan tambang sesungguhnya tidak bisa hanya dilihat di area kerja semata. Mereka umumnya adalah perempuan yang memiliki suami dan anak. Status yang demikian mengharuskan mereka mampu berperan ganda, sebagai pekerja sekaligus sebagai ibu rumah tangga. Peran ganda perempuan yang selama ini digaungkan sekaligus diperdebatkan, sudah dijalani dalam kehidupan sehari-hari mereka. Meski kerasnya dunia tambang sudah diketahui banyak pihak, namun kenyataannya banyak perempuan yang bertahan di lapangan kerja tersebut. Penelitian ini menggali berbagai faktor yang melatarbelakangi keputusan perempuan memilih bekerja di tambang sekaligus mengetahui cara pekerja perempuan bernegosiasi dan beradaptasi dengan lingkungan kerja tersebut. Selain itu, penelitian ini mengungkap bagaimana mereka memaknai pekerjaannya jika dikaitkan dengan konsep emansipasi. 
Lebih dalam lagi, penelitian ini menggali cara pekerja tambang menjalankan peran gandanya sebagai pekerja di sektor publik dan dalam rumah tangganya.

\section{Metode Penelitian}

Penelitian ini dilakukan menggunakan pendekatan kualitatif dengan metode penelitian fenomenologi. Pemilihan pendekatan kualitatif ini diyakini sesuai dengan realitas sosial sesungguhnya yang akan diungkap dalam penelitian ini, khususnya terkait perilaku komunikasi pekerja perempuan di tambang. Creswell dan Poth (2018: 45) mengatakan "We conduct qualitative research when we want to empower individuals to share their stories, hear their voices, and minimize the power relationship that often exist between a researcher and the participants in study".

Pemilihan metode fenomenologi dalam penelitian ini dilatarbelakangi oleh beberapa hal. Penelitian ini didasarkan pada pengalaman hidup manusia dalam hal ini para perempuan pekerja tambang. Dalam penelitian ini, pengalaman hidup perempuan pekerja tambang diharapkan akan menjadi alat untuk memahami secara lebih baik kehidupan sosial budaya perempuan, khususnya yang bekerja di tambang. Creswell dan Poth menjelaskan, " $a$ phenomenological study describes the common meaning for several individuals of their lived experiences of concept or a phenomenon. Phenomenologists focus on describing what all participants have in common as they experience a phenomenon" (2018: 75). Pemilihan metode ini juga mengacu pendapat Streubert \& Carpenter (2011: 23) yang menjelaskan "The purpose of phenomenology is to explore the live experience of individual. Phenomenology provides researchers with the framework for discovering what it is like to live an experience".

Penelitian dilakukan di tambang batubara PT Kaltim Prima Coal (KPC) yang berlokasi di Sangatta-Kutai TimurKalimantan Timur. Informan penelitian ini berjumlah 10 orang pekerja perempuan tambang yang selanjutnya disebut operator. Jumlah ini mengacu pendapat Creswell yang mengatakan 'For a phenomenological study, the process of collecting information involves primarily in-depth interviews with as many as 10 individuals'(1998:122).

Pemilihan informan didasarkan pada lamanya masa kerja, status pernikahan, dan prestasi di tempat kerja. Data terkait hal tersebut diperoleh dari Divisi Human Resources dan departemen tempat operator perempuan bekerja. Penerapan kriteria ini diharapkan informan benar-benar memiliki kapabilitas karena pengalamannya dan mampu mengartikulasikan pengalaman dan pandangannya terkait hal-hal yang dipertanyakan. Berdasarkan hal tersebut, informan sengaja dipilih yang memiliki masa kerja lebih dari 10 tahun. Hal tersebut mengacu pendapat Van Manen dalam Creswell dan Poth (2018: 153) yang menyebutkan "In $a$ phenomenological study, the participants may be located at a single site, although they need not be. Most importantly, they must be individuals who have all experienced the phenomenon being explored and can articulate their lived experiences".

Pengumpulan data dilakukan melalui observasi, wawancara, dan dokumentasi. Peneliti melakukan observasi dengan 
turun langsung ke area tambang agar bisa melakukan pengamatan mendalam terhadap rutinitas kerja informan. Dalam penelitian ini informan adalah para pekerja perempuan di tambang yang dikenal sebagai operator. Hal ini mudah dilakukan karena peneliti sendiri bekerja di tambang yang sama, meski pada posisi berbeda. Peneliti melakukan wawancara mendalam, baik di lokasi kerja maupun di rumah informan guna merekonstruksi realitas yang ada.

Peneliti melakukan wawancara dua kali untuk masing-masing informan. Pertama, peneliti memberikan daftar pertanyaan tertulis sekaligus menjelaskan maksud setiap pertanyaan untuk memberi kesempatan informan memahami apa yang akan digali. Kedua, peneliti menemui informan kembali untuk melakukan wawancara mendalam. Pertanyaan yang diajukan tidak terstruktur dan proses wawancara dilakukan dalam suasana santai. Pengumpulan data dilakukan melalui alat rekam dan tulisan sebagai cadangan jika hasil rekam mengalami kendala. Ketika wawancara pengambilan data sudah mencapai saturasi, maka pengumpulan data dihentikan. Saturasi menunjukkan bahwa data yang dideskripsikan partisipan memiliki kesamaan atau mencapai titik jenuh dilihat dari berbagai perspektif (Streubert \& Carpenter, 2011: 30). Dalam penelitian ini saturasi diperoleh pada informan kelima, sehingga data dari informan lainnya hanya digunakan sebagai pembanding.

Selanjutnya peneliti melakukan analisis data yang dimulai dengan pendiskripsian seluruh pengalaman informan yang diperoleh selama wawancara. Data penelitian dianalisa dalam tiga tahap, yaitu reduksi data, penyajian data dan kesimpulan atau verifikasi data. Dalam tahap reduksi data, peneliti membuat rangkuman hasil wawancara dilanjutkan dengan pengkodean. Hasil wawancara dalam bentuk bahasa diringkas dalam frase pendek untuk menangkap esensi pesan dari tiap operator yang diwawancarai. Pengkodean data dilakukan dengan dramaturgical coding, dimana data terkait tujuan, konflik, taktik, sikap, dan emosi yang dirasakan informan dimaknai secara detail. Mathew B. Miles, Michael Huberman dan Johnny Saldana (2014: 76) mengatakan 'Dramaturgical coding is appropite for exploring intrapersonal and interpersonal participant experience and actions in case studies, power relationship, and the processes of human motives and agency'.

Peneliti membuat coding dalam bentuk tema, seperti alasan perempuan memilih bekerja di tambang, cara bernegosiasi dan beradaptasi, pemahaman tentang emansipasi untuk memaknai profesinya, dan cara mereka menjalankan peran gandanya. DeSantis dan Ugarriza dalam Streubert \& Carpenter mengatakan 'a theme is an abstract entity that brings meaning identity to a recurrent experience and its variant manifestations. As such, a theme captures and unifies the nature or basis of the experience into a meaningful whole'(2011:46). Selanjutnya setiap tema akan dihubungkan untuk mengembangkan uraian lengkap tentang pengalaman yang sedang diselidiki. Seperti yang disampaikan DeSantis dan Ugarriza 'In a phenomenological study, the researcher will relate the themes to one another to develop an exhaustive description 
of the experience being investigated'. Data dalam penelitian ini disajikan dalam bentuk teks naratif. Miles and Hubermen (2014:13) mengatakan 'the most frequent form of display data for qualitative research data in the past has been narrative text'.

\section{Hasil Penelitian dan Pembahasan}

\section{Pekerja Perempuan di Tambang PT KPC}

Berdasarkan Sustainable Report PT Kaltim Prima Coal (KPC) dan data Human Resources yang ada, KPC merupakan salah satu perusahaan tambang batubara terbesar di dunia yang terletak di Sangatta, Kabupaten Kutai Timur, Kalimantan Timur. Wilayah tambang perusahaan ini mencapai 90 ribu hektar. Dalam menjalankan operasinya, tambang tersebut didukung berbagai alat berat seperti dump truck, dozer, shovel, dan backhoe.

Kapasitas tiap alat berat mencapai ratusan ton. Perusahaan memulai penambangannya tahun 1990 dan saat ini mempekerjakan 4.708 karyawan. Khusus yang bekerja sebagai operator alat berat mencapai 1.802 orang. Di antara ribuan karyawan tersebut, tercatat 128 operator adalah perempuan. KPC telah menempatkan perempuan sebagai operator di tambang sejak tahun 1992. Latar belakang pendidikan operator perempuan pada umumnya adalah lulusan SMA. Sebagian besar operator perempuan merupakan penduduk asli Sangatta, sebagian yang lain berasal dari luar Kalimantan.

Tidak ada kebijakan khusus dan perbedaan dalam menjalankan pekerjaan bagi operator laki-laki dan perempuan di perusahaan ini. Baik operator laki-laki maupun perempuan bekerja dengan standar kerjaan sama. Meski secara fisik operator laki-laki dan perempuan berbeda, namun perempuan tidak dieksklusifkan pola kerjanya. Dilihat dari sisi pakaian semua operator harus melengkapi dirinya dengan standar safety ketat, seperti memakai sepatu safety, helm, dan rompi. Mereka juga dituntut mampu mengoperasikan alat berat yang sama. Jika laki-laki harus bekerja dalam shift malam hari, perempuan juga harus bisa menjalani rutinitas tersebut ketika gilirannya tiba.

Perempuan juga dituntut mampu mengoperasikan segala ukuran alat berat yang ada. Sebagai contoh, ketika laki-laki mengoperasikan truk dengan kapasitas angkut hingga 360 ton, perempuan juga harus mampu menjalani hal yang sama. Standar gaji yang mereka terima juga tidak ada perbedaan antara laki-laki dan perempuan. Di perusahaan ini, reward diperoleh atas dasar prestasi kerja bukan berdasarkan jenis kelamin ataupun gender. KPC memberlakukan standar keselamatan sangat ketat, dan hal itu berlaku bagi semua karyawan termasuk operator perempuan di tambang untuk menjaga keselamatan karyawan.

\section{Tambang: Harapan dan Tantangan}

Di Sangatta, KPC bukan satu-satunya perusahaan besar. Terdapat ratusan perusahaan besar lain yang mendukung operasi penambangan yang merupakan perusahaan multi nasional. Lapangan kerja selain sebagai operator alat berat terbuka lebar. Meski demikian, banyak perempuan yang justru lebih memilih menjadi operator. Seperti dituturkan Suryani, operator asal Sulawesi yang kini sudah 26 tahun bekerja, tahun 1992 saat dirinya melamar menjadi operator terdapat 90 perempuan lainnya yang juga melamar. 
Jumlah pelamar operator dari perempuan tetap mencapai ratusan orang hingga sekarang, setiap kali ada perusahaan tambang yang membuka lowongan operator. Inimenunjukkan animo perempuan terhadap dunia kerja tambang sangat tinggi. Berdasarkan data Divisi Human Resource (HR), jumlah pelamar pada pembukaan lowongan operator tahun 2009 mencapai 111 orang. Beberapa operator perempuan yang berhasil diwawancarai, memiliki persamaan alasan mengapa lebih memilih menjadi operator perempuan. Umandia, 44 tahun, single parent memiliki dua anak, masa kerja 26 tahun, mengatakan,

"Menjadi operator alat berat itu memang keinginan saya. Awal melamar saya hanya melihat alat berat yang harus dioperasikan lewat gambar. Begitu melihat langsung di tambang, saya justru tambah semangat. Waktu itu, yang ngoperasikan umumnya laki-laki. Saya tertantang kalau laki-laki bisa saya juga harus bisa. Jadi operator perempuan itu bangga... rasanya keren saja bisa nyetir mobil sebesar rumah" (Umandia, wawancara 18/8/2018)

Alasan Umandia hampir sama dengan operator perempuan lainnya. Sherly Tempang, 49 tahun, menikah memiliki 2 anak, masa kerja 26 tahun mengatakan :

"Dari awal saya memang ingin menjadi supir. Ketika lamaran saya diterima, saya dibawa ke tambang. Begitu melihat alat berat yang harus saya kendarai, saya jutru tertantang bukan takut. Meski belum mulai ngoperasikan alat itu, rasa bangga muncul karena akan ngoperasikan kendaraan yang segede rumah. Apalagi gaji yang akan saya terima lebih besar dari tempat kerja saya sebelumnya" (Sherly, wawancara $28 / 8 / 2018)$

Alasan yang sedikit berbeda datang dari Yenny Arista, 30 tahun, menikah memiliki 2 anak, masa kerja 12 tahun.

"Awalnya, saya melihat para operator perempuan berangkat kerja dengan pakaian tambang. Saya lihat keren dan gagah. Waktu itu usia saya baru
17 tahun, jadi belum terpikir kerja untuk cari uang karena masih hidup dengan orang tua. Saya memutuskan melamar menjadi operator karena bagi saya ini profesi yang menarik sekaligus menantang" (Yenny, wawancara 1/8/2018)

Apa yang disampaikan Yenny tidak berbeda dengan alasan Dewi Karticha, 28 tahun, single parent memiliki satu anak, masa kerja 10 tahun. Ia tertarik melamar operator karena melihat operator perempuan lain yang dianggapnya berpenampilan keren sekaligus ingin membuktikan bahwa perempuan mampu mengerjakan pekerjaan yang sama dengan laki-laki. Pernyataan para operator perempuan tersebut membuktikan bahwa mereka memilih bekerja sebagai operator tambang didasari alasan yang cukup kuat. Selain untuk presentasi diri, mereka juga ingin menunjukkan kesetaraan dalam profesi yang didominasi laki-laki. Menjadi operator juga menjadi harapan terciptanya kesejahteraan, karena mereka mendapat imbalan upah yang relatif lebih baik dibanding profesi lain. Berdasarkan data yang diperoleh saat wawancara, beberapa operator perempuan yang berstatus single parent' mampu membiayai anak-anaknya sampai kuliah.

Menurut Erving Goffman (1959) ada tiga fungsi utama dari presentasi diri. Fungsi paling mendasar dari presentasi diri adalah untuk mendefinisikan sifat sosial masyarakat. Kedua adalah untuk mendapatkan keuntungan materi dan penghargaan sosial. Fokus ketiga adalah membangun identitas tertentu untuk diri kita sendiri. Selanjutnya Goffman menjelaskan presentasi diri berkaitan dengan manajemen kesan. Orang-orang melakukan presentasi diri untuk mengelola kesan orang lain terhadap 
dirinya. Perempuan yang berprofesi sebagai operator tambang memiliki keterkaitan erat dengan teori tersebut. Orang tidak lagi melihat pekerja perempuan tambang sebagai makhluk yang lemah, sebagaimana penilaian yang diberikan pada kebanyakan perempuan selama ini.

\section{Negosiasi dan Adaptasi: Upaya Menakluk- kan Kerasnya Tambang}

Sejumlah teori dan fakta menunjukkan bahwa tambang bukan dunia kerja yang mudah dijalani bagi perempuan. Berbagai cara untuk bernegosiasi dan beradaptasi dengan kondisi tersebut harus mereka lakukan. Suryani mengaku pernah mencakar dan memukul teman kerja laki-laki saat baru masuk kerja menjadi operator.

"Tahun 1992, perempuan yang menjadi operator masih sangat sedikit. Ketika ada perempuan masuk di pekerjaan itu seolah masih aneh bagi pekerja laki-laki. Kami bersama-sama saat berangkat dan pulang kerja. Ketika dalam bis ada yang mencolek saya. Spontan saya cakar dan pukul orang itu pakai helm. Sejak saat itu, mereka gak berani godain saya. Tidak hanya itu, mereka (laki-laki) juga kadang sanksi ....apakah saya bisa bekerja di tambang. Sekarang saya sudah 26 tahun menjalani profesi ini. Mereka justru balik memuji ternyata saya kuat dan bisa menjalani rutinitas yang sangat berat ini. (Suryani, 20/8/2018)

Berbeda dengan Suryani, Sherly punya cara tersendiri untuk bernegosiasi dan beradaptasi di tambang.

"Sebelum kerja disini, saya kerja di Matahari. Tiap hari saya berdandan full make up . Kebiasaan itu saya bawa di tambang. Sering laki-laki komentar...bibir merah nih yee. Saya gak marah, justru saya balas menggoda "suka ya". Lama-kelamaan mereka bosan godain saya. Akhirnya memutuskan untuk tidak pakai make up. Untuk apa di tengah hutan dandan. Dengan melepas make up saya merasa lebih nyaman". (Sherly, 28/8/2018)

Tidak semua operator memiliki pengalaman serupa. Yenny dan Karticha tidak menemui hambatan berarti saat pertama memasuki dunia tambang. Keduanya memasuki tambang saat perusahaan sudah memberlakukan sejumlah kode etik dalam berkomunikasi sesama karyawan. Namun demikian, suara sumbang yang bersifat tidak yakin akan kemampuan perempuan pernah mereka rasakan.

"Yenny: Karena postur tubuh saya kecil, kadang operator laki-laki bilang..."emang kamu kuat kerja di tambang? Badan kamu saja sekecil itu". Saya jawab ya kuat dong. Mereka tidak langsung percaya, malah balik komentar "kita tunggu saja berapa lama kamu bisa bertahan". Setelah saya membuktikan bisa bekerja hingga 12 tahun, mereka (laki-laki) bilang "ternyata kamu kuat ya, salut perempuan dengan postur kecil seperti kamu bisa bekerja membawa alat berat". (Yenny, 11/8/2018)

"Karticha: Ketika saya mengikuti pemilihan operator top gun (terbaik) di departemen saya, banyak operator cowok yang komentar kalau saya gak mungkin menang. Setelah saya berhasil menyisihkan sekitar 700 operator lainnya dan bisa mewakili perusahaan ke tingkat Asia, baru mereka bilang "ternyata perempuan mampu menjadi yang terbaik. Setelah itu, banyak operator cowok yang suka nanya-nanya cara mengoperasikan alat berat yang baik dan aman". (Karticha, 31/8/2018)

Jika dihubungkan dengan teori tentang gender, kondisi yang dipaparkan para informan di atas merupakan manifestasi pemahaman konsep kultural yang membuat perbedaan antara laki-laki dan perempuan dalam hal peran, perilaku, mentalitas, dan karakteristik emosional. Pemahaman konsep tersebut sekaligus memunculkan konflik diantara para operator yang notabenenya memiliki perbedaan latar belakang budaya. Ting-Toomey dalam West-Turner (2010: 458) mengatakan "conflict is often present when members from two different culturesindividualistic and collectivistic-come together and that individuals will use a 
number of different conflict styles". Meski demikian, pengalaman para operator perempuan ini membuktikan bahwa mereka memiliki berbagai cara untuk bernegosiasi dan beradaptasi dengan keadaan, seperti tindakan secara fisik yang dilakukan Suryani, melawan dengan kata-kata seperti yang dilakukan Sherly, ataupun hanya sekedar mempertontonkan hasil kerja seperti yang dilakukan Yenny dan Kartika.

Mereka melakukan facework yang sangat bagus dalam menghadapi persoalan yang ada. Stella Ting-Toomey and Leeva Chung dalam West-Turner mengatakan 'facework is about the verbal and nonverbal strategies that we use to maintain, defend, or upgrade our own social self-image and attack or defend (or 'save') the social image of others' (2010: 452). Kesuksesan operator perempuan menangani konflik, membawa dampak yang signifikan. Operator laki-laki yang semula menyepelekan kemampuan kerja operator perempuan berubah menjadi pujian, menempatkan perempuan sebagai partner, hingga menjadikannya guru tempat bertanya.

Operator perempuan tidak hanya berhasil dalam hal negosiasi dan adaptasi dengan rekan kerja yang notabenenya lakilaki. Mereka juga mampu menaklukkan kerasnya tambang dan pola kerja malam yang merupakan rutinitas sangat berat. Berdasarkan data keselamatan yang ada, belum pernah ada catatan Lost Time Injury (LTI) di tambang KPC yang melibatkan operator perempuan dari tahun 1992 hingga sekarang. Selain itu, prestasi kerja perempuan juga menunjukkan hasil yang menggembirakan terbukti munculnya beberapa operator perempuan dengan predikat "the best operator" yang berhak mewakili perusahaan di tingkat Asia.

Mereka menunjukkan kemampuan bernegosiasi dan beradaptasi bukan dalam waktu sesaat. Tercatat $90 \%$ operator perempuan di tambang ini telah bekerja lebih dari 10 tahun, bahkan di antara mereka ada yang masa kerjanya di atas 25 tahun. Realita tersebut menggambarkan bahwa mengotakkan tambang dengan isu gender, dimana perempuan dianggap tidak cocok di dalamnya, tidak sesuai dengan realita di lapangan. Anggapan tambang sebagai dunia kerja laki-laki bahkan dibantah keras oleh para operator perempuan yang sudah menjalani rutinitas tersebut. Seperti yang disampaikan Umandia:

"Saya tidak setuju kalau tambang dianggap dunia kerja laki-laki. Buktinya saya bisa kerja di sini hingga 26 tahun ini. Alhamdulillah dari awal sampai sekarang saya merasa enjoy".

\section{Emansipasi Tanpa Retorika}

Kesetaraan antara laki-laki dan perempuan di tambang bisa dikatakan sebuah kesetaraan mutlak. Perbedaan mereka hanyalah secara bentuk fisik. Dilihat dari sisi tanggung jawab, beban kerja, dan kehidupan keseharian di tambang, tidak ada yang berbeda antara laki-laki dan perempuan. Ketika di tempat lain perempuan sibuk dengan pembicaraan emansipasi, perempuan di tambang sibuk berkarya. Mereka bahkan tidak begitu paham apa itu emansipasi, seperti yang disampaikan Suryani.

"Saya kurang tahu apa itu emansipasi. Bagi saya yang penting bisa bekerja dengan baik, saya bisa 
mengerjakan pekerjaan yang sama dengan lakilaki dan mendapat upah yang sama".

\section{Pendapat serupa disampaikan Sherly:}

"Bagi saya, emansipasi itu perempuan bisa mengerjakan pekerjaan laki-laki. Tapi saya bekerja bukan karena mikirin emansipasi. Saya memang punya niatan kerja, meski penuh tantangan".

\section{Komentar lebih ekstrim dilontarkan} Umandia:

"Menjadi operator adalah rutinitas yang harus saya lakukan. Saya bisa membiayai anak-anak saya karena saya bekerja sebagai operator. Tidak pernah terlintas kerja untuk menunjukkan emansipasi".

Sementara Karticha melihat dari sisi yang sedikit berbeda:

"Bagi perempuan, pekerjaan sebagai operator merupakan wujud kesetaraan dengan laki-laki. Itu artinya kami melakukan emansipasi. Tapi saya tidak pernah sibuk dengan pembicaraan emansipasi, yang penting kerja dengan baik untuk mendapatkan karir terbaik".

Berdasar temuan di lapangan, nampak jelas bahwa pekerja perempuan di tambang tidak menyadari bahwa profesinya merupakan bagian dari emansipasi. Kalaupun ada yang memahami hal tersebut, mereka lebih suka fokus bekerja dibanding harus beretorika sebagai pejuang emansipasi.

\section{Peran Ganda: Antara Kodrat dan Identitas Diri}

Selain menjalani emansipasi, para pekerja perempuan di tambang juga menjalani peran ganda. Mereka umumnya adalah perempuan yang berkeluarga dan memiliki anak. Selain menjadi operator, mereka adalah seorang ibu dan istri. Secara umum peran ganda perempuan diartikan sebagai dua atau lebih peran yang harus dimainkan oleh seorang perempuan dalam waktu yang bersamaan. Adapun peran-peran tersebut umunya mengenai peran domestik sebagai ibu rumah tangga dan peran publik yang umumnya dalam pasar tenaga kerja (Rustiani, 1996: 60). Operator perempuan di tambang KPC menjalani peran ganda sebagai rutinitas tanpa beban. Berdasar wawancara terhadap para operator yang menjadi informan, mereka mengaku :

"Kalau giliran masuk shift pagi, saya bangun jam 05.30 pagi. Saya masak untuk anak dan suami, siapkan keperluan sekolah. Saya tidak tenang di kerjaan kalau belum melakukan tugas tersebut. Meski saya bekerja, tapi tugas rumah tetap kewajiban saya sebagai ibu dan istri. Kalau hari off saya full temani anak belajar dan main. Sebenarnya suami gak mengharuskan saya kerja, kalau merasa capek suruh berhenti”. (Yenny, 11/8/2018)

"Kodrat saya sebagai perempuan adalah mengurus keluarga. Kalau saya bekerja itu karena saya butuh biaya dan pengin mencari kesibukan positif di luar rumah. Saya senang bisa masak untuk anak dan merawat mereka. Bagi saya menjalankan dua kegiatan itu bukan beban". (Umandia, 18/8/2018)

"Suami saya memiliki jabatan cukup tinggi di tambang. Dia melarang saya bekerja agar bisa konsentrasi urus rumah. Saya tidak mau berhenti kerja, karena saya menyukai kerjaan itu. Saya berusaha buktikan ke suami, meski saya kerja sebagai operator tetapi urusan rumah akan tetap beres. Bagi saya bekerja bukan sekedar uang, tapi kepuasan". (Sherly, 28/8/2018)

"Sebenarnya suami saya cukup penghasilannya untuk keluarga. Tapi saya ingin punya penghasilan sendiri untuk menambah ekonomi keluarga. Tiap hari saya bangun jam 4 subuh, dibantu suami masak dan nyiapkan keperluan anak-anak. Saya tidak beban karena orang tua saya mengajarkan kodrat saya sebagai perempuan tidak boleh dilupakan meski saya kerja di luar rumah". (Suryani, 20/8/2018)

"Saat masuk shift pagi, saya tiba di rumah jam 8 malam. Saya tidak langsung istirahat tapi nyempatkan menemani anak belajar dan nyiapkan bahan masakan besuk pagi. Awalnya berat tapi lama kelamaan nyantai. Sebagai single parent saya harus bisa ngerjakan semua sendiri. Jika tiba waktu off saya akan ajak anak saya jalan untuk refreshing". (Karticha, 31/8/2018) 
Pernyataan para operator tersebut menunjukkan kemampuan mereka membagi peran domestik dan publik. Kesuksesan mereka menjalani peran ganda tidak terlepas dari pemikiran tentang kodrat perempuan yang harus mereka jalani. Selain itu, keinginan mempertahankan profesinya sebagai bagian identitas diri, menjadi pemicu kuat mereka tetap bekerja. Kedua hal tersebut menjadi dasar tidak adanya masalah yang timbul akibat peran ganda yang merekajalani. Profesi gandayang mereka jalani berdampak positif pada terbukanya peluang kerja bagi perempuan lain. Mereka umumnya mampu membayar asisten rumah tangga untuk membantu kerjaan di rumah, khususnya untuk jaga anak. Keuntungan lainnya adalah mereka memiliki kemampuan mengatur waktu sangat baik, kapan harus kerja di luar, di rumah, dan kapan harus istirahat.

Seperti yang disampaikan Umandia,

"Saya harus pandai membagi dan memanfaatkan waktu agar tetap bisa istirahat. Hal-hal yang tidak berguna seperti ngumpul-ngumpul sekedar untuk ngrumpi paling saya hindari”.

Pernyataan Umandia ini tidak berbeda dengan pendapat operator perempuan lainnya. Dengan kata lain, maksimalisasi peran ganda mereka justru berdampak sangat positif, khusunya jika dikaitkan dengan kemampuan manajemen waktu.

Peran ganda yang mereka mainkan sekaligus bukti keberhasilan negosiasi perempuan tidak hanya di tempat kerja melainkan juga di rumah tangganya. Mereka berhasil meyakinkan suaminya bahwa pekerjaan luar rumah yang ditekuninya tidak akan berdampak buruk terhadap perannya dalam rumah tangga. Seperti pengalaman Sherly misalnya, ia berhasil meyakinkan suaminya untuk tidak berhenti bekerja. Suaminya yang berpenghasilan sangat memadai sebagai seorang supervisor sesungguhnya tidak menginginkan istrinya bekerja. Namun dengan berbagai alasan yang sangat rasional, Sherly bisa meyakinkan suaminya hingga ia bisa mempertahankan pekerjaannya.

\section{Simpulan}

Berdasar hasil penelitian dan pembahasan di atas, bisa disimpulkan bahwa ada beberapa faktor yang melatarbelakangi perempuan memilih kerja di tambang adalah keinginan membuktikan diri bahwa perempuan mampu bekerja dalam dunia kerja yang umumnya didominasi laki-laki. Faktor lainnya adalah keinginan memperoleh pendapatan yang relatif besar untuk memenuhi kebutuhan hidup. Selain itu, perempuan juga ingin menjadikan profesi ini sebagai presentasi diri.

Ada beberapa cara yang mereka lakukan dalam melakukan negosiasi dan adaptasi. Sebagian operator perempuan melakukan dengan tindakan tegas, sebagian yang lain melawan dengan kata-kata, dan ada pula yang bernegosisasi dengan cara menunjukkan prestasi kerja. Cara negosiasi yang mereka lakukan berdampak positif yang ditunjukkan dengan perubahan sikap pekerja laki-laki terhadap pekerja perempuan. Operator lakilaki yang semula menyepelekan kemampuan kerja operator perempuan berubah menjadi pujian, menempatkan perempuan sebagai partner, hingga menjadikannya guru tempat bertanya.

Pekerja perempuan di tambang memaknai emansipasi hanya dengan kerja keras dan menunjukkan kemampuan bekerja yang sama dengan laki-laki. Mereka umumnya 
tidak terlalu memikirkan bahkan tidak peduli dengan konsep emansipasi. Mereka melakukan emansipasi tanpa retorika.

Substansi penelitian ini memberikan masukan tentang peran ganda perempuan. Ketika menjalankan peran gandanya, pekerja perempuan di tambang memahami tugas dalam rumah tangga sebagai kodrat yang harus dijalani. Sedangkan bekerja di tambang dianggap sebagai identitas diri secara sosial. Pemahaman tersebut menjadikan mereka mampu menggabungkan tugas di sektor publik dan domestik dengan sangat baik. Ketika di rumah, mereka menjalani rutinitas sebagai ibu rumah tangga, sedang di tempat kerja mereka akan fokus pada pekerjaan yang harus diselesaikannya.

\section{Daftar Pustaka}

Babcock, Linda., \& Laschevar, Sara. (2003). Women Don't Ask: Negotiation and the Gender Divide. UK: Princeton University Press.

Cresswell, J. W., (1998), Qualitative Inquiry and Research Design: Choosing Among Five Traditions $\left(2^{\text {nd }}\right.$ ed). USA: Sage.

Cresswell, J. W., \& Poth, C. (2018). Qualitative Inquiry \& Research Design Choosing Among Five Aproaches (4 ${ }^{\text {th }}$ ed.).USA: Sage.

Fakih, Mansour (2013). Analisis Gender \& Transformasi Sosial. Yogyakarta: Diandra Primamitra.

Goffman, Erving. (1959). The Presentation of Self in Everyday Life. Edinburgh: University of Edinburgh Social Sciences Research Centre.

Hayes, John.(2002). Interpersonal Skills at Work (2nd Edition). New York: Routledge.

Houghtaling, Melissa K. (2009). Book
Review, Harriet Bradley, Gender: Key Concepts. Canadian Journal of Sociology, Vol 34, No 3, 944-946.

Lahiri-Dutt, Kuntala. (2004). Gender Survey of Kaltim Prima Coal Sangatta, East Kalimantan, Indonesia. Canberra, Australia. ANU press.

Lahiri-Dutt, K. \& Robinson, K. (2008). Bodies in contest: Gender difference and equity in a coal mine. Abingdon, England: Routledge.

Littlejohn, Stephen W. dan Karen A. Foss (2008). Theories of Human Communication $\left(9^{\text {th }}\right.$ ed). USA: Wadsworth

Miles, Mathew.B, Hubermen, Michael, \& Saldana, Johny. (2014). Qualitative Data Analysis: A Method Sourcebook. USA: Arizona State University.

Nugroho, Riant. (2008). Gender dan Strategi Pengarusutamaannya di Indonesia. Yogyakarta: Pustaka Pelajar.

Robinson, Kathryn. (1996). Woman, mining and development, in R. Howitt, J. Connel and P. Hirsch (eds) Resources, Nations and Indigenous Peoples, Melbourne: Oxford University Press.

Rustiani, F. (1996). Istilah-Istilah Umum dalam Wacana Gender, dalam Jurnal Analisis Sosial: Analisis Sosial: Analisis Gender dalam Memahami Persoalan Perempuan, Edisi 4/November 1996, Yayasan Akatiga, Bandung.

Streubert, Helen. J, \& Carpenter. (2011). Qualitative Research in Nursing: Advancing the Humanitic Imperative $\left(5^{\text {th }}\right.$ ed). China: Library of Congres Cataloging-in-Publication Data.

Ting-Toomey, Stella. (1999). Communicating Across Cultures. New York: The Guilford Press

PT Kaltim Prima Coal 2016. (2017). Sutainable Development Report. Jakarta: Subur Printing. 
Tierney, Helen. (1999). Women's Studies Encyclopedia. New York: Green Wood Press.
West, Richard. \& Turner, Linn,H. (2010). Introducing Communication Theory $\left(4^{\text {th }}\right.$ ed). New York: McGraw-Hill Companies. 